\title{
O PROFESSOR-ENGENHEIRO E A METAMORFOSE: A NECESSIDADE DA FORMAÇÃO DIDÁTICO-PEDAGÓGICA
}

DOI: 10.37702/2175-957X.COBENGE.2021.3643

Sãhmara Silva Muniz - sahmara.muniz@live.com

Evolução Centro Educacional

Av. Bahia 353

45810-000 - Porto Seguro - BA

Resumo: Esse artigo objetiva salientar a ideia do desenvolvimento ideal do professor-engenheiro com a necessidade da formação didático-pedagógica. Ao comparar a metamorfose da borboleta com o desenvolvimento do preparo do docente universitário, a preocupação desse estudo é apresentar a importância de, além dos saberes específicos do conteúdo a ser lecionado, o professor deve compreender os estudos específicos referentes à docência universitária. Através da contribuição de autores como Laudares (2008 e 2010), Behrens (2011), Matos et al.(2014), Giusti e Monteiro de Aguiar (2004), entre outros, a pesquisa bibliográfica procurou identificar os motivos pelos quais é imprescindível esse preparo docente, mesmo não sendo amparado pela LDB (Lei de Diretrizes e Bases da Educação Nacional), e as consequências da falta desse preparo para o docente, e também ao discente universitário da área da Engenharia. Concluiu-se a emergência da necessidade do estímulo ao preparo didático, além das titulações de mestrado e doutorado dos Professores-Engenheiros, para aperfeiçoamento do processo de crescimento, ou pode-se dizer, processo de metamorfose desse profissional. As pesquisas analisadas ainda enfatizam a necessidade da continuidade de estudos relacionados à reformulação do sistema de carreiras docentes, além do estímulo da inclusão, nas grades curriculares dos cursos de pós-graduação, matérias como Didática do Ensino Superior ou Metodologia do Ensino Superior.

Palavras-chave: Engenheiro. Professor. Metamorfose. Formação didático-pedagógica. Docência Universitária. 


\section{O PROFESSOR-ENGENHEIRO E A METAMORFOSE: A NECESSIDADE DA FORMAÇÃO DIDÁTICO-PEDAGÓGICA}

\section{INTRODUÇÃO}

O ciclo de vida de uma lagarta passa por fases de desenvolvimento até que chegue à sua plenitude, na forma da borboleta. Para essa transformação, o pequeno ser, ainda imaturo, se prepara ao alimentar-se até que chegue ao estágio de pupa (onde muitas espécies desenvolvem o casulo para sua proteção), e ali é onde a verdadeira metamorfose acontece. Depois desse período de transição, ao sair da pupa, podemos contemplar a beleza das cores e detalhes da borboleta, em sua completude.

O processo do crescimento e evolução do aluno de Ensino Superior até chegar à fase de Professor Universitário - de maneira ideal - pode ser comparado à beleza da metamorfose de uma borboleta. $O$ discente alimenta-se e absorve o conhecimento durante a sua graduação até ao passo de finalização dessa fase, de modo que, após passar pelo processo de sua formação didático-pedagógica (a pupa), alcance a inteireza da harmonia e dinâmica da prática da Docência Universitária.

Em contrapartida ao ideal, é comum encontrar relatos de alunos universitários que criticam a didática, ou a falta dela, dos professores acadêmicos, além do prejuízo do discente quanto à aprendizagem e absorção do conhecimento ocasionado principalmente por esta falta de preparo dos docentes. Em geral, são exímios bacharéis, com uma atuação destacada em sua área profissional, com títulos de mestres e doutores, porém, sem um devido preparo didático-pedagógico para atuar no Ensino Superior.

No campo de Estudo da Engenharia - domínio que será analisado nesse artigo assim como em outras, senão quase todas, áreas acadêmicas (GIUSTI e MONTEIRO DE AGUIAR, 2004), é possível observar que a formação exigida dos professores é limitada ao profundo conhecimento do assunto a ser ministrado, ao considerar que critérios para uma boa avaliação docente envolvem a sua produção acadêmica e/ou titulação.

Nesse contexto, é analisado por Giusti e Monteiro de Aguiar (2004), que, nada, ou quase nada, tem sido exigido dos docentes em teor pedagógico, além de questionarem se as titulações de mestrado e doutorado, "do modo como vem sendo realizada, possa contribuir efetivamente para a melhoria da qualidade didática do Ensino Superior" (GIUSTI e MONTEIRO DE AGUIAR, 2004, p.1).

As autoras ainda acrescentam que a própria legislação de educação brasileira não dá um amparo que motive aos docentes se formarem pedagogicamente. Ao citarem a LDB (Lei de Diretrizes e Bases da Educação Nacional), mostram a omissão dessa lei no que diz respeito à formação pedagógica do professor universitário.

No projeto inicial da nova LDB, ainda em 1992, tendo por autor, o então Senador Darcy Ribeiro, o suporte em relação à formação pedagógica do docente de Ensino Superior era visto como necessário, e foi apresentado e discutido por Saviani (1998):

Art. 74 - A preparação para o exercício do magistério superior se faz, em nível de pós-graduação, em programas de mestrado e doutorado, acompanhados da respectiva formação didático-pedagógica, inclusive de modo a capacitar o uso das modernas tecnologias do ensino.

Porém, em 1996, mediante alterações e "enxugamentos" dos textos da LDB (Lei 9.394/96), como mencionam Giusti e Monteiro de Aguiar (2004), suprimiu-se a necessidade 
da formação didático-pedagógica, exigindo somente a titulação. Dessa maneira, o artigo ficou como: "Art. 66 - A preparação para o exercício do magistério superior far-se-á em nível de pós-graduação, prioritariamente em programas de mestrado e doutorado.". (LDB - Lei 9.394/96)

Mediante a perceptível falta de incentivo para a formação pedagógica dos docentes universitários, objetiva-se nesse artigo, através do embasamento teórico de autores como Laudares (2008 e 2010), Behrens (2011), Matos et al.(2014), entre outros, buscar e abrir caminhos, dentro do campo de Ensino da Engenharia, do porquê, além de docentes titulados, necessita-se alimentar a graduação com Engenheiros-Professores, que tenham a vontade e o propósito da devida competência pedagógica para a melhora efetiva do Ensino Superior.

\section{DESENVOLVIMENTO}

Quando se fala sobre o processo da formação do docente-engenheiro, é necessário voltar à origem desse transcurso: o aluno universitário na Engenharia e como ele enxerga a formação pedagógica.

As Diretrizes Curriculares Nacionais (DCN) definem os princípios, fundamentos, condições e procedimentos da formação de engenheiros (BRASIL, 2002), e estas reproduzem as orientações das DCN recomendadas para todos os outros cursos (BRASIL, 2001). Na 11 $1^{\text {a }}$ Resolução/2002, encontra-se a instituição das DCN para o Curso de Engenharia, que delimita o perfil do formando engenheiro:

Art. 3ㅇ O Curso de Graduação em Engenharia tem como perfil do formando egresso/profissional o engenheiro, com formação generalista, humanista, crítica e reflexiva, capacitado a absorver e desenvolver novas tecnologias, estimulando a sua atuação crítica e criativa na identificação e resolução de problemas, considerando seus aspectos políticos, econômicos, sociais, ambientais e culturais, com visão ética e humanística, em atendimento às demandas da sociedade. (BRASIL, 2002)

Dessa maneira definido, o egresso formando, quase sempre não considerando a docência como futura opção de ofício, além de levar em conta o fato de que a LDB não obriga a formação pedagógica para o docente universitário (como mencionado na introdução desse estudo), o discente considera as disciplinas humanísticas do currículo da Engenharia - aquelas não relacionadas aos "saberes técnicos-práticos" - como "perfumaria", desvalorizando as competências pedagógicas da mesma forma (LAUDARES, 2008).

Depois de formado, o Engenheiro está sob a Lei 5194/66 que regulamenta essa profissão e inclui, em seu artigo $7^{0}$ na letra e, entre outras, a atribuição de ensino. Essas atividades estão sancionadas na Resolução 1010/2005, onde o Conselho Federal de Engenharia, Arquitetura e Agronomia "dispõe sobre a regulamentação da atribuição de títulos profissionais, atividades, competências e caracterização do âmbito de atuação dos profissionais inseridos no Sistema Confea/Crea" (CONFEA, 2005), definindo o que é formação e competência, além de mostrar os meios para alcançá-las:

"VI - Formação profissional: processo de aquisição de competências e habilidades para o exercício responsável da profissão;

VII - Competência profissional: capacidade de utilização de conhecimentos, habilidades e atitudes necessários ao desempenho de atividades em 
campos profissionais específicos, obedecendo a padrões de qualidade e produtividade;" (CONFEA, 2005)

Ao passo que a Lei 5194/66 e a Resolução 1010/2005 validam, dentre as várias atribuições a engenheiros, arquitetos e agrônomos, a atividade do ensino (docência), encontra-se uma discrepância nos programas e currículos de graduação, onde a sua minoria apresenta disciplinas que corroborem a essa atribuição, conforme mencionado anteriormente.

Laudares (2010), ao fazer uma pesquisa com um grupo de Professores-Engenheiros para reconhecer o campo de ensino na Engenharia, colhe que a ingressão na docência quase nunca é uma escolha inicial, mas dá-se por um "emaranhado de relações", que envolvem em porcentagens bem proporcionais: "gostar de estudar; oportunidade; influência de familiares; experiências escolares positivas; experiência com treinamento empresarial; ser bom orador; falta de identificação com profissão de formação" (LAUDARES, 2010), e uma pequena minoria que envolve o ingresso no magistério por escolha pessoal.

O autor também apresenta que, boa parte do que os professores sabem sobre ensino provém de suas experiências ao decorrer de sua história de vida, considerando que na Engenharia é comum a inserção do profissional liberal ao magistério. Esse professor então traz a sua bagagem de realidade profissional e suas "representações, imagens e crenças sobre o que é ser professor" (LAUDARES, 2010) - apreendido durante sua vida de escola, enquanto aluno - para a entrada em sua nova profissão, a de professor.

Em sua pesquisa, Laudares (2010) delimita três modelos de EngenheirosProfessores, considerando as características que envolvem o ensino e didática desses docentes, sendo eles: o "Prático-Artesanal", onde o "aprender-fazendo" tem a base para suas aulas, demonstrando a docência como algo distante do ideal; "Técnico ou Academicista", que envolve o docente que é mais envolvido com extensas produções acadêmicas e valoriza o conhecimento científico e teórico, como a melhor técnica para didática de ensino e o Professor "Hermenêutico ou Reflexivo", sendo uma minoria que mescla o que é ensinado em classe com o que acontece na vida prática do engenheiro.

Obviamente, a diversidade de experiências enriquece a qualidade da formação dos graduandos, mas quando o profissional liberal que atua na docência universitária o faz de forma improvisada, há uma tendência de ter-se uma docência com raros sucessos, e de ensaios e erros que perduram durante muitos anos ao decorrer de sua carreira, como confirma Behrens (2011), prejudicando o discente do Ensino Superior que tem contato com esse profissional.

De acordo com o já mencionado sobre a LDB de 1996, encontra-se como requisito à docência universitária, a titulação de mestre e doutor. Dessa maneira, o incentivo à produção acadêmica como critério para uma boa avaliação docente, torna-se um problema em si mesmo, como salienta Behrens (2011), ao apresentar que esses profissionais com titulação geram dificuldades à gestão, ao solicitar fatidicamente a diminuição de carga horária na docência, com a argumentação de se ter mais horas para suas pesquisas.

Por conseguinte, nota-se que, quando cursos de formação - mais especificamente nos mestrados e doutorados - são voltados exclusivamente para pesquisa e deficientemente não atendem às necessidades das atividades de docência, oportuniza a titulação ao professor, mas, como descreve Giusti e Monteiro de Aguiar (2004), não retrata a melhoria na qualidade de ensino.

O objetivo ao apresentar esses dados não é diminuir a importância de mestrados e doutorados, mas salientar que, para a formação de um professor acadêmico é necessário, além da formação específica das disciplinas a serem lecionadas, a formação pedagógica, 
valorizando assim, a indispensabilidade dos saberes do ensino, auxiliando na transição de aprendiz experiente (discente de pós-graduação) para professor novato.

Behrens (2009, p.61) citada pela mesma autora anos depois, Behrens (2011), coloca como ponto de proveitosa reflexão ao professor que opta pela docência, tomar consciência de que, "ao adentrar a sala de aula, o seu papel essencial é o de ser professor" (BEHRENS,2011). Dessa maneira, a autora confirma o argumento de que é necessária a formação pedagógica e não somente a experiência de que um "bom docente nasce feito", ratificando o fato de que ser um bom Engenheiro não quer dizer ser um bom Professor de Engenharia.

Nesse aspecto, Ribeiro e Cunha citados por Vaz e Gilberto (2014), também defendem a necessidade de, além dos saberes relacionados à formação profissional do Engenheiro, se ter uma preocupação em relação aos saberes sobre a educação, afirmando:

"...percebe-se, cada vez com mais clareza, que o domínio dos conhecimentos das especificidades científicas é importante, mas insuficiente para responder a complexidade dos problemas que emergem na prática cotidiana de sala de aula". (RIBEIRO e CUNHA apud VAZ e GILBERTO, 2014).

O Brasil, nos últimos anos, teve um crescimento significativo na oferta e demanda de cursos de graduação, vivenciando um crescimento científico e tecnológico, inclusive na área de Engenharia. Nessa perspectiva, Oliveira (2011) citado por Matos et al. (2014) apresenta dados analisados pelo Observatório de Ensino de Engenharia que mostram a evolução de um aumento de $189,49 \%$ nos números de cursos de graduação na área, entre os anos de 2001 a 2010, passando de 771 a 2.232 formações.

Matos et al. (2014) observam que, esse desenvolvimento da área de Engenharia, acarreta à necessidade do aumento do número de docentes, levando-os a aspiração de estudar a forma como esses professores tem sido formados.

Devido a essa expansão no ensino superior, há um público consideravelmente heterogêneo, que até então não tinha acesso ao estudo universitário, mas hoje faz parte de uma geração conectada com as inovações tecnológicas. Isto posto, o professor que adentra nesse universo, está sujeito a encontrar um grupo que, como Giusti e Monteiro de Aguiar (2004) apresentam, é:

\footnotetext{
"Um público que pode, por um lado, não estar tão bem preparado, tanto emocional quanto intelectualmente, para o ingresso no ensino superior; [...] mas um público que pode, por outro lado, ser muito mais exigente quanto à qualidade do curso oferecido, tendo em vista especialmente o alto grau de competitividade do mercado de trabalho." (GIUSTI e MONTEIRO DE AGUIAR, 2004)
}

A inovação tecnológica traz um perfil de alunos diferente do que já houvera há alguns anos, pois este discente chega à graduação com uma série de informações previamente adquiridas via internet.

As autoras ainda apresentam que, devido à cobrança sobre o novo perfil de egressos do ensino superior, o professor universitário tem de estar a par dessas exigências, analisando as circunstâncias atuais e se adequando às novas técnicas de ensino, tornando sua docência pertinente nessa mudança e no contexto que ela está envolvida. E Laudares (2008) corrobora essa necessidade com a formação continuada para Engenheiros, concedendo a "capacitação de Professores de Engenharia em função das mudanças tecnológicas e das necessidades pedagógicas." (LAUDARES, 2008, p.13) 
Dessa maneira, para responder aos impactos tecnológicos sobre os discentes universitários, Longo (2010) citado por Matos e outros (2014) prescreve que o perfil do professor também tem que ser alterado, de modo que o retrato tradicional do docente transmissor de informações seja substituído por um papel "facilitador, supervisor, orientador e animador do processo educacional junto ao alunado" (MATOS et al., 2014), centralizando, assim, as atividades no desenvolvimento desse novo perfil de aluno.

A desconsideração no sentido dos aspectos pedagógicos e didáticos traz um prejuízo de 50\% em índice de evasão e retenção nos cursos de Engenharia (MATOS et al., 2014) acentuando o desgaste do modelo atual de docência adotado nos cursos da área.

Entre as dificuldades de ensino-aprendizagem vivenciadas pelos alunos, pode ser mencionada a falha na formação pedagógica do docente, termo destacado por Giusti e Monteiro de Aguiar (2004) citando Morosini (2000), quando relacionam o desempenho didático-pedagógico do professor e o desempenho na aprendizagem do aluno. Dessa maneira, além de trazer perda ao desenvolvimento discente, afeta, mesmo que de forma indireta, a avaliação da qualidade e capacidade didática do docente - embora não tenha normas do Sistema Nacional relacionadas à formação pedagógica do ProfessorEngenheiro.

Ratificando essa consideração, Bazzo e outros (2000) citado por Laudares (2010) julga como fundamental para a melhoria de ensino na Engenharia a formação específica para a docência, "visando a superação de um modelo tradicionalista e conservador de ensino" (LAUDARES,2010), acompanhando a expansão e mudança no público graduando. É visto como positiva, por vários autores, essa preocupação sobre a importância da formação didática do Professor-Engenheiro. Entre eles, Lopez (2008) apresenta, em sua pesquisa sobre os novos graduados segundo o critério de convergência europeu, como desafio a formação e preparação do docente-engenheiro para agir diante de um contexto de mudanças que exigem adequações curriculares, flexibilidade e trabalhos interdisciplinares requeridos atualmente nos cursos de Engenharia.

Ao citarem Benedito, Ferrer e Ferreres (1995), Giusti e Monteiro de Aguiar (2004) apresentam que a função do Professor excede, sobremaneira, à docência apenas. Além dessa, apontam a necessidade do contínuo aprofundamento na área de ensino, envolvendo a pesquisa e estudo; a inovação e a comunicação das atualizações tecnológicas; a tutoria e acompanhamento da avaliação dos discentes; participação na gestão acadêmica; a avaliação pessoal e de outrem sobre a docência e a investigação; contribuição no clima de colaboração ente professores, além do estímulo a atividades de intercâmbio de departamentos e interuniversitário.

Ao analisar essas funções tão abrangentes, haja vista os argumentos acima apresentados como as características necessárias a um Engenheiro-Professor universitário é inegável a argumentação em prol da importância da formação pedagógica desse profissional, considerando a complexidade dos saberes necessários para um docente universitário, sendo fundamental o conhecimento específico da matéria a ser lecionada, além da compreensão dos saberes instrutivos educacionais.

\section{CONCLUSÃO}

Ao longo dessa pesquisa, apresentou-se, entre outros aspectos, a necessidade da formação didático-pedagógica do Engenheiro-Professor no campo universitário. Pode-se constatar que, parte considerável dos Professores-Engenheiros se tornem professores propriamente ditos ao decorrer de sua trajetória na docência, lecionando - entre erros e acertos - com suas experiências pré-profissionais e com o acúmulo de bagagem durante a sua prática do ensino. 
Entre os aspectos que justificam a importância do preparo didático-pedagógico do Engenheiro-Professor, foram destacados: 1) O risco do desvio de função ao professor incentivado pela titulação; 2) O crescimento do ensino superior; 3) Novo perfil do aluno Universitário; 4) As inovações tecnológicas e como isso afeta ao discente do Ensino Superior; 5) Necessidade de mudança no perfil de professores universitários, considerando as exigências do mercado ao egresso formado Engenheiro; 6) Índice considerável de evasão e retenção de alunos e as dificuldades no ensino-aprendizagem; 7) Pouca ligação entre a formação atualmente apresentada em cursos de pós e a melhora do ensino universitário.

Tendo em conta o apresentado nesse artigo, unido às apreciações concernentes à falta de didática-pedagógica habitual entre professores universitários de forma mais específica entre os Engenheiros-Professores, como apresentado em diversas pesquisas como as de Giusti e Monteiro de Aguiar (2004), Laudares (2008 e 2010), Behrens (2011), Matos et al.(2014), entre outros, pode-se constatar a crescente necessidade da formação pedagógica na docência universitária.

Nesse sentido, deixa-se a sugestão para continuidade de estudos relacionados à reformulação do sistema de carreiras desses profissionais, passando a valorizar, de forma mais concreta, à docência. Nessa perspectiva, alguns cursos de pós-graduação Lato Senso ou Stricto Senso já tem incluído, em suas grades curriculares, matérias como Didática do Ensino Superior ou Metodologia do Ensino Superior. Considerando essa prática ainda escassa, recomenda-se a continuação do estudo, para o estímulo do ensino preparatório de docência aos pós-graduandos, através de habilidades específicas, preparando-o para a atuação no ensino, na extensão e na pesquisa, como um processo conjunto.

Como apresentado na introdução desse estudo, a metamorfose completa de uma borboleta, envolve um processo que culmina num resultado belíssimo de se contemplar. Esse processo, quando mal concebido, acarreta em sequelas, podendo ocasionar uma máformação da borboleta. Da mesma maneira, o processo formativo do professor, quando mal desenvolvido, provocará prejuízos, não somente para o educador, mas inclusive e principalmente ao estudante universitário, que faz parte imprescindível do processo de metamorfose desse docente.

Arrematando de forma conclusiva, fazem-se nesse artigo as palavras de Giusti e Monteiro de Aguiar (2004) ao citarem Benedito, Ferrer e Ferreres (1995), apelando à emergência da formação didático-pedagógica dos docentes universitários, quando anunciam: "A docência universitária é importante e a formação de seus profissionais já não admite demora."!

\section{Agradecimentos}

A Deus, a Ele sempre a toda a honra e glória.

A minha família, em especial ao meu esposo, pelo apoio e ajuda diariamente na lida da docência e incentivo à busca pelo conhecimento.

\section{REFERÊNCIAS}

BEHRENS, M. A.. Docência universitária: formação ou improvisação? Educação, Santa Maria, v. 36, n. 3, p. 441-454, set./dez. 2011. Disponível em: <https://periodicos.ufsm.br/reveducacao/article/view/2976/24 23>. Acesso em: 04 jan. 2017. 
BRASIL. Lei n. 9.394/96 de 20 de dezembro de 1996. Lei de diretrizes e bases da educação nacional. Diário Oficial da República Federativa do Brasil, Brasília, DF, no. 248, dez. 1996, Disponível em: <http://www.planalto.gov.br/ ccivil_03/leis/L9394.htm> Acesso em: 05 jan. 2017.

BRASIL. Ministério da Educação. CNE/CES. Parecer nํ583, de 4 de abril de 2001. Orientação para as diretrizes curriculares dos cursos de graduação. Diário Oficial da República Federativa do Brasil, Poder Executivo, Brasília, DF, 2001. Disponível em: <http://portal.mec.gov.br/cne/arquivos/pdf/CES0583.pdf>. Acesso em: 10 jan. 2017.

BRASIL. Ministério da Educação. CNE/CES. Resolução no. 11/2002, de 11 de março de 2002. Institui diretrizes curriculares nacionais dos cursos de graduação em engenharia. Diário Oficial da República Federativa do Brasil, Poder Executivo, Brasília, DF, 2002. Disponível em: <http://portal.mec.gov.br/cne/arquivos/pdf/CES112002.pdf>. Acesso em: 10 jan. 2017.

BRASIL. Lei № 5.194, de 24 de dezembro de 1966. Regula o exercício das profissões de engenheiro, arquiteto e engenheiro-agrônomo, e dá outras providências. Diário Oficial da República Federativa do Brasil, Poder Executivo, Brasília, DF, 1966. Disponível em: <http://www.planalto.gov.br/ ccivil_03/Leis/L5194.htm>. Acesso em: 10 jan. 2017.

CONFEA. Resolução № 1.010, de 22 de agosto de 2005. Dispõe sobre a regulamentação da atribuição de títulos profissionais, atividades, competências e caracterização do âmbito de atuação dos profissionais inseridos no Sistema CONFEA/CREA, para efeito de fiscalização do exercício profissional. Conselho Federal de Engenharia, Arquitetura e Agronomia, Brasília, DF, 2005. Disponível em: $<$ http://normativos.confea.org.br/ementas/visualiza.asp?idEmenta=550>. Acesso em: 10 jan. 2017.

GIUSTI P, G.; MONTEIRO DE AGUIAR P., E.. A importância da formação didáticopedagógica e a construção de um novo perfil para docentes universitários. RIE Revista Iberoamericana de Educación, Número 33/4, jul.2004. Disponível em: <http://www.centroetica.uct.cl/documentos/archivos/PDF/T3\% 2004.pdf> Acesso em: 04 jan. 2017.

LAUDARES, J. B.. A descoberta da docência por engenheiros-professores e suas representações. In: XXXVIII Congresso Brasileiro de Educação em Engenharia. 2010. Fortaleza-CE. Anais Eletrônicos. Disponível em:

<http://www.abenge.org.br/CobengeAnteriores/2010/artigos/380.pdf> Acesso em: 05 jan. 2017

LAUDARES, J. B.; PAIXÃO, E.L.; VIGGIANO, A.R. O ensino de engenharia e a formação do engenheiro: contribuição do programa de mestrado em tecnologia do CEFET-MG - Educação Tecnológica. Revista de Ensino de Engenharia, v.27, n.1, p.816, 2008. Disponível em:

<http://www.abenge.org.br/revista/index.php/abenge/article/view/56>. Acesso em: 10 jan. 2017. 
LOPEZ, M. R. Los nuevos postgrados según los criterios de convergencia euperia influencia en las ingenierías. Revista de Ensino de Engenharia, v.27, n.3, p.45-51, 2008. Disponível em: <http://www.abenge.org.br/revista/index. php/abenge/article/view/65/46>. Acesso em: 11 jan. 2017

MATOS, M. M.; PEREIRA, R. M.; IAOCHITE, R. T.; FERNANDES, R. S. A formação do professor em nível superior de engenharia: uma visão a partir da leitura da revista de ensino de engenharia. In: Congresso Brasileiro de Educação em Engenharia. 2014. Juiz de Fora - MG. Anais Eletrônicos. Disponível em:

<http://www.abenge.org.br/cobenge-2014/Artigos/128871 .pdf>. Acesso em: 05 jan. 2017

SAVIANI, D.. A nova lei da educação: trajetória, limites e perspectivas. $4^{a}$ ed.

Campinas-SP: Autores Associados, 1998.

VAZ, A. J.; GILBERTO, I. J. L.. O engenheiro docente no curso de arquitetura e urbanismo: percepções dos alunos sobre o bom professor. In: Congresso Brasileiro de Educação em Engenharia. 2014. Juiz de Fora - MG. Anais Eletrônicos. Disponível em: <http://www.abenge.org.br/cobenge-2014/Artigos/128565.pdf>. Acesso em: 05 jan. 2017

\title{
THE TEACHER-ENGINEER AND METAMORPHOSIS: THE NEED FOR DIDATIC- PEDAGOGICAL TRAININGIN
}

\begin{abstract}
This article aims to emphasize the idea of the ideal teacher-engineer development with the need of didactic-pedagogical training. When comparing the metamorphosis of the butterfly with the development of university teacher training, the concern of this study is to present the importance of knowledge specific to the subject to be taught, the teacher must understand the specific studies relating to university teaching. Through the contribution of authors like Laudares (2008 and 2010), Behrens (2011), Matos et al. (2014), Giusti and Monteiro de Aguiar (2004), among others, the bibliographical research sought to identify the reasons why it is essential that teacher preparation, although not supported by the LDB (Lei de Diretrizes e Bases da Educação Nacional - Law of Guidelines and Bases for National Education, in Brazil), and the consequences of the lack of this preparation for the teacher and University engineering student. It was concluded the emergence of the need of stimulating educational preparation, in addition to the titles of master's and doctoral degrees of the teachers-engineers, for improvement of growth process, or it can be said, that professional metamorphosis process. The research analyzed still emphasize the need for continuity of studies related to the reformulation of the career system faculty, in addition to encouraging the inclusion, in the curricular grids of postgraduate courses, subjects such as Higher Education Didactics or Methodology of Higher Education.
\end{abstract}

Keywords: Engineer. Teacher. Metamorphosis. Didactic-pedagogical training. University Teaching. 